\title{
Graduate Finalists Compete for Awards at 1991 MRS Fall Meeting
}

At the 1991 MRS Fall Meeting in Boston, 18 finalists will compete for the MRS Graduate Student Awards to be presented on Wednesday evening during ceremonies also honoring the 1991 Von Hippel and MRS Medallist recipients.

Graduate Award Finalists, all authors or co-authors of papers to be presented at the Fall Meeting, were selected based on the quality and thoroughness of their research, originality and independence of their contributions, and their promise for future achievement in materials research.

During two special sessions on Tuesday, December 3, the finalists will give brief talks explaining their research to a panel of judges who will select the award recipients. Among the judges will be organizers from the symposia in which the finalists are participating, members of the MRS Awards Committee, and other MRS representatives. MRS Fall Meeting participants are also invited to attend.

Following is a list of the finalists, where they are studying, their paper titles, and the symposium in which they are participating.

\section{Graduate Student Award Finalists}

1991 MRS Fall Meeting

Christopher Paul Burmester, University of California, "Simulation of Y-Ba-Cu-O Epitaxial Growth and Microstructure Formation" (Symposium Cb).

Qi-Zhong Cao, University of Massachusetts at Amherst, "Scaling Behavior of the External Perimeters of the Site-Percolation Clusters in Three Dimensions" (Symposium P).

Samuel P. Gido, Massachusetts Institute of Technology, "Constant Mean Curvature Models for the Structure of Grain Boundaries in Lamellar Diblock Copolymers" (Symposium O).

Jung-Chun Andrew Huang, University of Mlinois at Urbana-Champaign, "Novel Epitaxial Growth and Surface OrderDisorder Transition of $\mathrm{CU}_{3} \mathrm{AU}(110)$ and $\mathrm{CU}_{3} \mathrm{AU}(111)^{\prime \prime}$ (Symposium $\mathrm{Ca}$ ).

Ken Khachaturyan, University of California, Berkeley, "Surface Acoustic Wave Detection of Large Lattice Relaxation

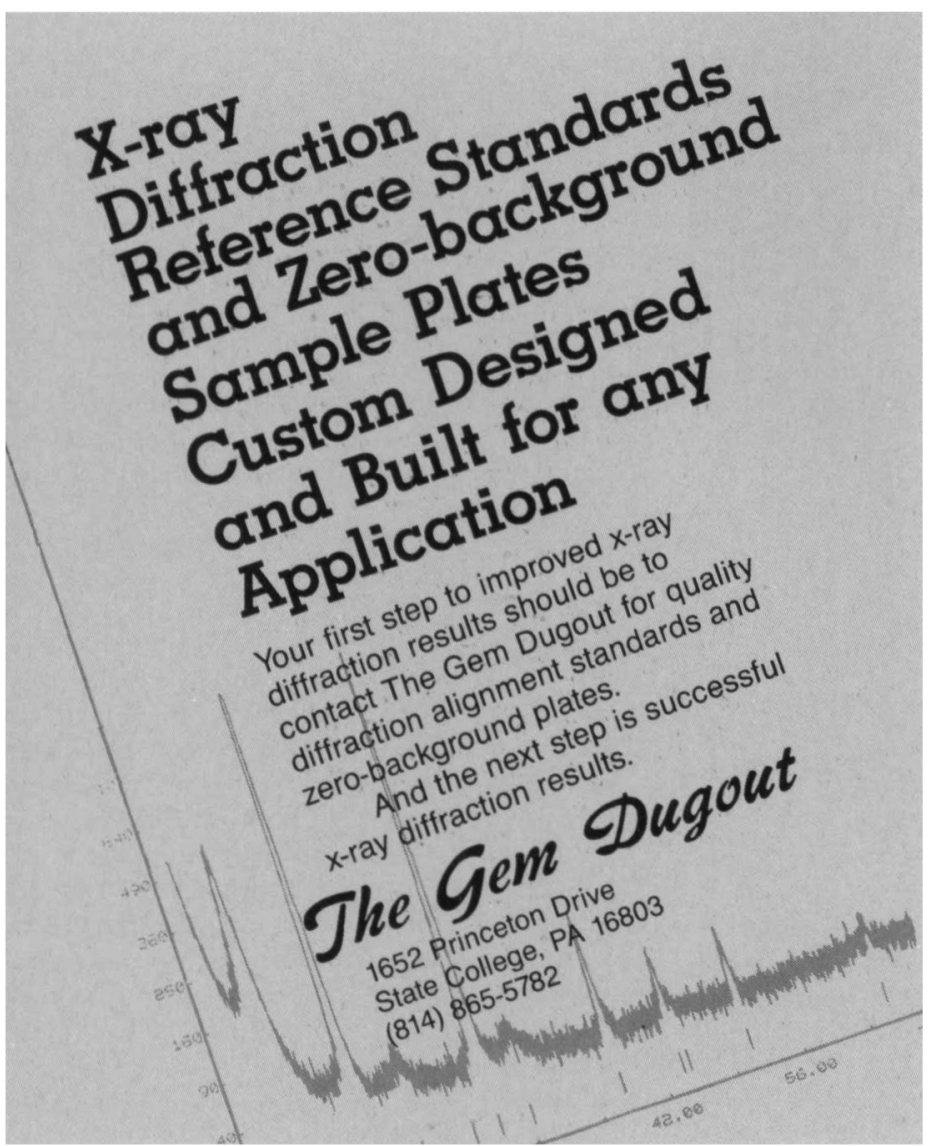

of Metastable EL2 in LT-GaAs" (Symposium F).

Milo D. Koretsky, University of California, "Enhancement of Photoresist Etch Rates by Argon Metastables in a Plasma Afterglow Reactor" (Symposium B).

Ting Lei, Boston University, "Epitaxial Growth of GaN on Different Faces of Silicon by ECR-Assisted MBE" (Symposium G).

Phillip B. Messersmith, University of Illinois at Urbana-Champaign, "Synthesis and Properties of PVA/Calcium Aluminate Nanocomposites" (Symposium K).

David J. Mooney, Massachusetts Institute of Technology, "Induction of Hepatocyte Differentiation by the Extracellular Matrix and an RGD-Containing Synthetic Peptide" (Symposium T).

Yasukazu Murakami, University of Tsukuba, Japan, "Crystallographic Study of the Stress-Induced $\beta_{2}{ }^{\prime \prime \rightarrow} \rightarrow 7 R$ Martensitic Transformation in a Ni-37.0 at. \% Al Alloy" (Symposium M).

Brian L. Olmsted, University of Rochester, "Dependence of Interdiffusion in AlGaAs on Stoichiometry Between Ga-rich and As-rich Solidus Limits" (Symposium E). Laurent Sagalowicz, Ohio State University, "Dislocation Dissociation in the $\Sigma 13$ Boundary in Si" (Symposium Cb).

George Stejic, University of WisconsinMadison, "Depairing and Depinning Critical Currents in Superconducting Thin Films" (Symposium H).

Patricia M. Wilson, University of Michigan, "Lattice Bending in Poly(Diacetylene) Droplets Near Surfaces" (Symposium N).

Judy Zhihong Wu, University of Houston, "The Intrinsic Anisotropy Behavior in High Quality $\mathrm{YBa}_{2} \mathrm{Cu}_{3} \mathrm{O}_{7 d}(110)$ Films" (Symposium $\mathrm{H}$ ).

Jian-Zhong Yuan, SUNY at Albany, "A New Method for Measuring Ion Implantation Critical Dose In Situ" (Symposium A).

Jiang Yue, Ohio State University, "Proton Transport of Modified Sulfonated Polyaniline Electrode and Related Applications" (Symposium N).

Yuan-Jun Zhao, University of Houston, "Large Pinning Enhancement in LiDoped YBCO Sintered Material After Thermal Neutron Irradiation" (Symposium A). 